\title{
Social functioning and the quality of life of patients diagnosed with schizophrenia
}

\author{
Ewelina Dziwota', Marian Zdzisław Stepulak², Anna Włoszczak-Szubzda ${ }^{3,4}$, Marcin Olajossy \\ 1 II Clinic of Psychiatry and Psychiatric Rehabilitation, Medical University, Lublin \\ 2 Department of Pedagogy and Psychology, Laboratory of General Psychology and Psychological Diagnosis, Higher \\ School of Economics and Innovation, Lublin \\ ${ }^{3}$ Faculty of Health Sciences, Department of Nursing, Higher School of Economics and Innovation, Lublin \\ ${ }^{4}$ Department of Biostatistics, Demography and Epidemiology, Institute of Rural Health, Lublin
}

Dziwota E, Stepulak MZ, Włoszczak-Szubzda A, Olajossy M. Social functioning and the quality of life of patients diagnosed with schizophrenia. Ann Agric Environ Med. 2018; 25(1): 50-55. doi: 10.5604/12321966.1233566

\begin{abstract}
Introduction. Schizophrenia to a considerably great degree impairs the social functioning of the persons affected in the spheres of interpersonal and occupational contacts, as well as self-care. It brings about serious cognitive, perceptual, motor and emotional deficits, inevitably leading to the social withdrawal of patients. This phenomenon may assume various forms, from the limitations in interpersonal relations, through narrowing these relations to only some circumstances, to the total cessation of social contacts.

Objective. The objective of the study is presentation of the most important problems related with social functioning and quality of life of patients diagnosed with schizophrenia, based on scientific studies conducted in Poland and worldwide.

State of knowledge. The family of a schizophrenia patient exerts a great effect on the social functioning. While undertaking proper actions the family may become a co-therapist and significantly facilitate the patient's adjustment to life in society and his/her playing a specified role. Analysis of disorders in social functioning of patients with schizophrenia, in the context of social cognition, indicates the fact that these disorders have their source in the lack of capabilities for identification of own and other people's internal states, whereas mentalization is the essence of social cognition.

Conclusions. Therapy, any psychosocial impact as well as rehabilitation, neutralizes the causes for patients' withdrawal from social life. Training of social skills is necessary which teaches patients to return to the situation when they would be able to function properly in their environment.
\end{abstract}

Key words

mental illness, social cognition, family, psychosis, remission

\section{INTRODUCTION}

Antoni Kępiński, the outstanding Polish psychiatrist, scientist, humanist and philosopher, dedicated his book devoted to the problems related with schizophrenia to 'Those who feel more and understand differently, and therefore suffer more, whom we often call schizophrenics'[1].

This article presents the most important issues associated with social functioning and the quality of life of patients with schizophrenia, based on scientific studies conducted in Poland and worldwide.

\section{OBJECTIVE}

The objective of this study is to attract attention to the necessity for undertaking efforts by the general public concerning the restoration of complete wellbeing and possibility to play a social role by individuals suffering from schizophrenia.

State of knowledge - Conditioning of schizophrenia. Schizophrenia, with itsentire rich variety of psychopathological symptoms, significantly contributes to the deterioration of the social functioning of patients affected by this disease.

Address for correspondence: Marian Zdzisław Stepulak, Higher School of Economics and Innovation, Projektowa 4, 20-209 Lublin, Poland

E-mail: Marian.Stepulak@wsei.lublin.pl

Received: 30 November 2015; accepted: 15 June 2016; first published on January 2017
Social dysfunction - the deterioration of functioning in one or more basic spheres, such as: interpersonal contacts, work or self-care - according to the diagnostic-classification system (DSM IV-TR, DSM-5) [2] by the American Psychiatric Association (APA), is the primary criterion of schizophrenia. It is noteworthy that the sole concept of dysfunction was introduced to sociology by R. K. Merton who in this way described all the phenomena exerting a negative effect on the modification or adaptation of the social system [3]. In consequence of this dysfunction, the system is exposed to various types of deformations and tensions which, in turn, are neutralized with the participation of so-called functions.

Schizophrenia disturbs many aspects of the life of a patient, and brings about deficits in functioning: cognitive, perceptual, motor and emotional. Cognitive deficits should be understood as difficulties with thinking (including an excessive inclusiveness of thinking), and with the expression of thoughts. The capability for reasoning, attention and memory are impaired. Perceptual deficits are related with disability in the reception of stimuli. In turn, motor deficits designate unnatural postures, positions of the head and shoulders, or involuntary movements of the face and extremities (prolonged time of response to stimuli, problems with coordination and agility). Emotional deficit is a distorted capability for cognition and identification of emotions [4]. The above-quoted deficits in functioning lead to the social withdrawal of individuals suffering from schizophrenia, consisting in avoidance of social contacts, and inevitably 
leading to social isolation, and therefore, closing of the vicious circle of stigmatization of mentally ill individuals. Here, it is worth mentioning that social withdrawal is the symptom which may also occur in disorders other than schizophrenia, e.g. schizoidia, i.e. schizoidal personality disorder.

E. Jelastopulu et al, in their report entitled 'Correlation between the Personal and Social Performance Scale (PSP) and the Positive and Negative Syndrome Scale (PANSS)', in a Greek sample of patients with schizophrenia' undertook the problem of psychosocial dysfunction. It is one of the features of schizophrenia leading to the decrease in life independence and in the quality of life. Cognitive achievements and professional fulfilment, similar to social functioning, are approached as a determinant of response to treatment. The goal of the researchers was to assess the correlation between the Personal and Social Performance (PSP) Scale and PANSS in patients diagnosed with schizophrenia during routine clinical practice. The study showed that both scales provide convergent results [5].

Compromised neurocognition is a core feature of schizophrenia. Larger IQ impairments in the FE (first episode of schizophrenia) compared to the premorbid period, but comparable to later phases of illness suggests deterioration between premorbid and FE phases followed by deficit stability at the group level [6].

Mario Fioravanti et al., in 'A Meta-Analysis of Cognitive Deficits in Adults with a Diagnosis of Schizophrenia' identified 1,275 studies examining cognitive deficits in people with schizophrenia published between 1990 - 2003. Data from 113 studies were combined in a meta-analysis carried out on the five cognitive domains of IQ, memory, language, executive function, and attention. In all five cognitive domains, analysis indicated a consistent trend for patients to perform more poorly than healthy controls, with significant heterogeneity across studies [7].

Nina V. Kraguljac et al., in article the 'Memory Deficits in Schizophrenia: A Selective Review of Functional Magnetic Resonance Imaging (fMRI) Studies', mention cognitive deficits as the most predictive of long-term outcomes, with abnormalities in memory being the most robust finding. The advent of functional magnetic resonance imaging (fMRI) has allowed the exploration of neural correlates of memory deficits in vivo, working memory and episodic memory. However, fMRI studies of memory deficits in schizophrenia are far from universal [8].

Family system and social environment and quality of life of schizophrenia patients. $M$. Jarema has characterized the functioning of the family of a patient with schizophrenia, which is important while discussing problems related with his/her coping in society. The fact of contracting a serious mental disease has a seminal impact on the life of the whole family. The family then becomes a patient, co-therapist and a 'helping hand' in the return of the patient to society. For a patient suffering from schizophrenia, relations with the family may bring satisfaction or become an emotional burden. Relations between the patient and his/her family depend on the environment of origin, patterns of behaviour, social-cultural conditions in which the patient was brought up, as well as on the hierarchy of values which the family fosters and according to which it lives. Here, psychoeducation is very important, and the enrichment of family members' knowledge concerning the disease, working out a proper attitude towards the patient, full of warmth, understanding, tolerance, acceptance, provision of the sense of safety, and consequently, the restoration of the possibility to play a specified social role, despite incomplete psychical comfort [9].

In this context, it is worth taking a look at social dysfunction in schizophrenia from the perspective of social cognition, a problem which has been undertaken by many researchers, especially in recent years. Social cognition consists in the acquisition and shaping of subjective knowledge, which an individual uses in interactions with others. Its essence is mentalization. The theory of the brain, i.e. capability for mentalization, is the whole of the skills of ascribing oneself and others certain unobservable internal states in order to understand and explain social behaviours [10]. Therefore, there arises the question whether the deficit described in this theory of the brain finds its reflection in the social functioning of patients with schizophrenia?

P. W. Corrigan and R. Toomey, while measuring social cognition and cognitive functioning of patients, arrived at the conclusion that social cognition is more strongly associated with the indicator of social functioning, understood as the skill of coping in problem social situations, compared to cognitive functions. Furthermore, in recent years it has been empirically proven that the capability for mentalization, as the key aspect of social cognition, is an important factor explaining the social dysfunction of people suffering from schizophrenia. In these studies, the scale was used measuring the level of metacognition - the Metacognition Assessment Scale - the histories obtained from schizophrenia patients were evaluated with respect to understanding own brain and the brain of others, and reflection concerning stress [10].

Artur Ziółkowski et al., in the work 'An evaluation of life satisfaction and health - Quality of life of senior citizens' wrote about life satisfaction which is associated with subjective health evaluations. There are two domains (mental health and performance) that are positively evaluated by more than two-thirds of senior citizens. The observed differences challenge stereotypes and prejudices relating to negative aging process. Senior citizens have a chance of improving their control beliefs and develop self-regulation and coping skills [11].

J. Armijo, E. Mendez et al. conducted a study summingup the available research evidence from the last 14 years for the effectiveness of the strategy of environmental interventions in schizophrenia and other psychotic disorders. It seems that environmental efforts, combined with proper pharmacological treatment starting from the first episode of schizophrenia, considerably reduce negative symptoms, symptoms of psychosis, reduce the time of hospitalization, comorbidity with substance abuse, and improve general functioning, as well as the response to treatment. Psychoeducation of patients and their families reduces the level of auto-stigmatization; similarly, an increased patient knowledge concerning the disease and treatment. Local trainings of social skills significantly improve the social functioning of patients [12].

O. Elis, J.M. Caponigro and A.M. Kring in their report entitled 'Psychosocial treatments for negative symptoms in schizophrenia: Current practices and future directions' undertook the problem of psychosocial interventions, very important in rehabilitation and recovering from severe psychosis. Negative symptoms of schizophrenia are associated with deterioration in functioning and decrease in the quality 
of life; therefore, the treatment of negative symptoms becomes the priority. The presented shows the results of a review and evaluation of three years of treatment using the cognitivebehavioural therapy, i.e. social skills training (SST). The study mentions new forms of treatment which are important for the social functioning of a patient with schizophrenia, such as: Computer Based Training, Cognitive Flexibility Training, Cognitive Remediation Training, Cognitive Enhancement Training, Cognitive Sensory Training, and Loving Kindness Meditation [13].

J. S. Kwon and Jung-Soek Choi wrote about social functioning and the quality of life in the context of the measure of effectiveness in schizophrenia treatment. They found that atypical anti-psychotic drugs improve the quality of life (QOL) of patients with schizophrenia. In several control trials of anti-psychotic drugs, the scales of social functioning was used as a measure of the outcome of treatment, e.g. Social and Occupational Functioning Assessment Scale, Personal and Social Performance, and Medical Outcomes Study Short-Form 36 Health Survey. Short-term interventions were mainly investigated, thus, they did not precisely evaluate the changes in the social functioning of schizophrenia patients. At present in South Korea, clinical studies are being undertaken in order to evaluate an improvement in the social functioning of patients diagnosed with schizophrenia or schizoaffective disorder [14]. The Korean researchers draw attention to the fact that a scale for the evaluation of social functioning and QOL in clinical studies should be characterized by multidimensionality, reliable selection into a given population, and diagnosis made by clinicians, as well as capability for the examination of indistinguishable changes taking place during the course of the disease [12]. It should be added that the sense of social isolation, solitude, and the lack of interpersonal bonds which often occur among individuals suffering from schizophrenia, considerably decrease their satisfaction and quality of daily life.

M. Majkowicz and A. Zdun-Ryżewska undertook an attempt to evaluate the quality of life in schizophrenia. According to the encyclopaedia definition, the quality of life (QOL) is the degree of satisfaction of material and nonmaterial needs of individuals, families, and communities [14]. Common interest in the scope of problems concerning the quality of life was accompanied by the creation of various instruments for its measurement, also among schizophrenia patients. The occurrence of new anti-psychotic drugs resulted in an increase in the interest in measurements of the quality of life in this disease, which was examined from various clinical and social aspects. The quality of life of patients with schizophrenia is a subjective assessment, because patients evaluate their lives with their own eyes, and carry out this observation from the physical, cultural and social aspects, as well as from the aspect of the standard and comfort of life [16].

Instruments for measurement of the quality of life. Nevertheless, M. Majkowicz mentions the following, objective instruments for the measurement of the quality of life in metal diseases:

- Community Adjustment Form (CAF) - this instrument is a half-structured survey, which serves the evaluation of life satisfaction and quality of life, and the objects of evaluation are areas such as: activities during leisure time, life standard, history of employment, present occupational status, income, contacts with friends, with family, legal problems, satisfaction with life, self-esteem, quality of medical care, etc.

- Quality of Life Checklist (QLC) - this instrument provides information indispensable for planning a therapeutic schedule. The entire questionnaire consists of items which are evaluated by the respondent in two dimensions: 'satisfactory', or 'unsatisfactory'.

- Satisfaction with Life Domains Scale (SLDS) - an instrument developed in order to evaluate the effectiveness of the Community Support Program in New York which was created with a view of the chronically and severely mentally ill.

- Oregon Quality of Life Questionnaire (OQLQ) - at the basis of this questionnaire lies the theory which assumes that the quality of life is related with a specific relation of an individual with the surroundings, while his/her needs are satisfied to the degree to which this individual responds to the expectations imposed by the environment. This instrument examines functioning in many areas, such as: psychological distress, psychological wellbeing, tolerance to stress, independence, interpersonal interactions, work at home, employment, occupational activity, role of a souse, sensible time management, and negative consequences related with alcohol and drugs abuse.

- Lehman Quality of Life Interview - evaluation of the life situation of severely mentally ill patients in the area with which they actually deal, their current life experiences, and in the sphere of emotions and feelings evoked in them in a given situation.

- Quality of Life Scale - developed in order to assess negative symptoms in patients with schizophrenia. It covers such areas as: activities of daily life, interpersonal relationships, feeling of sense in life, motivation, curiosity, anhedony, pointless activity, empathy, emotional interactions and satisfaction with occupational activity.

- Client Quality of Life Interview - the theory which lies at the heart of this test assumes that certain domains exert a greater effect than others on the quality of life; the goal of the test is to determine these appropriate domains of life. The test covers such areas as: life necessities, i.e. food, clothing, shelter, health, hygiene, money and safety, as well as occupational training, education activities of daily life and leisure, privacy, social support, time spent with significant others, possibility to rely on oneself and peace of mind.

- California Well-Being Project Client Interview - a test developed by, among others, people subjected to treatment, contains open questions.

- Lancashire Quality of Life Profile - measures the quality of life and life satisfaction in patients with severe mental disorders, within the scope of nine dimensions: work/ education, leisure time, religion, finances, life conditions, safety, family relations, social relations and health. In addition, it allows evaluation of the general wellbeing and self-esteem.

- Quality of Life Self-Assessment Inventory.

- Quality of Life Index for Mental Health.

- Quality of Life Interview Scale [17]. 


\section{Diagnosis of the functioning of a schizophrenia patient in social and cultural space}

Undoubtedly, considering the nature of schizophrenia is not only the evaluation of the clinical status of the patient, but also the determination of his/her social functioning, as well as an indication of social and cultural factors which may have an effect on the long-term prognosis. One of the studies prospectively evaluated social functioning of patients hospitalized for the first time with the diagnosis of schizophrenia [18]. A group of patients was observed, and an improvement was noted after discharge from hospital, which manifested itself in the patients' recovery from isolation. The examined group of patients showed a greater inclination towards social engagement in the field of interest with the surroundings and making contacts with others. The problems which still remained were: self-care, maintenance of adequate personal hygiene, concern about appearance, tidy environment, nutrition, management of money and moving about the surroundings. The studies showed that women coped better in the area of recovering from isolation, whereas after a one-year observation - with respect to independence at work and employment. The study, conducted twice, confirmed a negative correlation between the intensity of symptoms according to the PANSS and social functioning, both among males and females. After a one-year observation, more than $10 \%$ of respondents still presented symptoms of a relatively high intensity. Within the scope of all the above-mentioned dimensions of functioning the patients obtained worse results, compared to the control group [18].

Y. Zhou, R. Zhou, W. Li et al. in their study 'Controlled trial of the effectiveness of community rehabilitation for patients with schizophrenia in Shanghai, China', undertook the scope of problems concerning social functioning and the quality of life with respect to patients suffering from schizophrenia living in Shanghai. The objective of the study was assessment of the effectiveness and effects of efforts by rehabilitation services carried out within social care institutions on psychotic symptoms and functioning of individuals with schizophrenia and, based of these results, the creation of a theoretical model of rehabilitation based on the environment. Among a group of 60 patients using the services of the Sunshine Soul Park (an aid institution providing day-care, psychological advice, recreation, and trainings of social skills), results in the scales ITAQ (Insight and Treatment Attitude Questionnaire), SDSS (Social Disability Screening Schedule), GQOLI-74 (Generic Quality of Life Inventory -74) and PANSS, showed a considerable improvement compared to the control group. Thus, efforts undertaken by environmental aid institutions are very important in the improvement of the quality of life of patients with schizophrenia [19].

Rehabilitation programmes for patients with the diagnosis of schizophrenia combine various psychosocial interventions, including trainings of social and life skills, implementation of prevention programmes, psychoeducation of families, and organization of therapeutic communities. In a study conducted in Croatia, 50 patients from the study group were treated for six months using the Rehabilitation Day Centre (RDC). The levels of the Quality of Life (MANSA), Social Functioning (OSA), and self-esteem (Rosenberg) were measured prior to and after the intervention. The study confirmed that patients with the implemented rehabilitation programme achieved better results in the social functioning, a higher level of the quality of life, and had a higher selfesteem [20].

H. Nakamura, N. Watanabe and E. Matsushima in a report entitled 'Structural equation model of factors related to quality of life for community-dwelling schizophrenic patients in Japan', also undertook the problem of the quality of life in schizophrenia. This study showed that the sense of self-efficacy and self-esteem, apart from marital status, age, severity of the course of schizophrenia, and the type of pharmacotherapy applied, considerably affect the quality of life. In the light of the above-mentioned factors, the sense of self-efficacy is an exceptionally strong factor in the determination of the level of the quality of life. Therefore, of importance are any undertakings aimed at training social skills based on the CBT, and engagement of patients in playing certain roles in society, family, and the environment in order to improve the sense of self-esteem and better self-image [21].

While discussing the functioning of mentally ill patients in Polish society it is worth referring to the report from studies conducted by the Central Bureau for Public Opinion (CBOS) of August 2008 [22]. This report places emphasis on the following issues:

- How are mentally ill patients defined?

- Perception of behaviours of mentally ill individuals.

- Do mentally ill individuals have a chance for recovery?

- Attitude towards compulsory treatment of those who are mentally ill.

- Do mentally ill individuals bring about shame for patients and their families?

- Evaluation of the attitude towards mentally ill people.

- Social distance towards those mentally ill.

- Are mentally ill patients discriminated in Poland?

J. Wciórka, while discussing the results of studies conducted by the $\mathrm{CBOS}$, drew general conclusions concerning the existence of the mentally ill in contemporary society. It turned out that in the Polish language neutral words with respect to the mentally ill are not common, the majority are pejorative terms, to a great degree stigmatizing these patients. Within recent years, the image of mentally ill individuals has slightly changed to their benefit, in the direction of being less stereotyped. An increasing number of people consider that patients with mental diseases have a chance to regain health. Always, unchangeably - writes J. Wciórka - there continues the conviction that a metal disease is shameful and requires it being hidden from the environment. The issue of durability of social acceptance of the use of compulsory treatment of mentally ill patients cannot be clearly interpreted, because, on the one hand, this is an expression of trust in medical services and specialists in the domain of psychiatry, while on the other hand, it may suggest in a certain sense an incomplete respect for individual freedom. The phenomenon of stigmatization is common in Polish society, which leads to the lack of granting the right to fully participate in social life to those who have had a previous mental illness, even when the difficult phase of an active illness is over. J. Wciórka underlined that the majority of Poles accept former patients of psychiatric hospitals as close neighbours or friends, which creates opportunities to undertake actions on behalf of a more full presence in the social life of people with the experience of a mental disease. According to the results of studies, mentally ill persons are constantly perceived as a group which is discriminated in many domains of social 
life, treated worse in employment, with lower respect for personal dignity, difficulties with respect to the right to education, protection of property and execution of justice. Despite the observed changes for the better in the awareness of Poles, they are not properly prepared for meeting their fellow countrymen suffering from mental disorders [22].

The report from the 'White Book' issued by the Institute of Patient Rights and Health Education concerning schizophrenia patients in Poland contains a chapter 'Schizophrenia and society', in which the following problems are considered:

- social consequences of contracting schizophrenia;

- importance of the first hospitalization;

- attitude of society towards persons with schizophrenia;

- stigmatization by mental disease;

- position of mentally ill patients in Poland [23].

A. Araszkiewicz unequivocally states that in schizophrenia there occurs the disturbance of the patient's relations with the environment, and atrophy of social skills. The chronic schizophrenic process leaves an imprint on the functioning of an individual at work, in relations with the environment, and with respect to self-care. It was found that in the United States patients with schizophrenia and affective bipolar disorder constitute one-third of 600,000 American homeless, and $16 \%$ of those in prison. Moreover, approximately $45 \%$ of patients with schizophrenia use assistance provided by centres for social support, such as environmental self-help centres, occupational therapy workshops, or former patients clubs. Nearly a half of patients with schizophrenia report a decrease of personal or family income as a result of the disease [23]. The 'White Book' emphasizes the role of the first hospitalization and diagnosis of schizophrenia for further social functioning. Many patients, after the first psychiatric hospitalization, use health benefit or premature pension, discontinue education, or are fired from work due to mental disease. Mentally ill individuals, especially those with psychotic disorders, are perceived in Polish society as behaving incomprehensively, talking nonsense, neglecting their appearance, and manifesting anxiety in behaviour. Such opinions lead towards the social stigmatization of those who are mentally ill, associated with the tendency for clear separation of 'them' from 'us'. Clinical observations indicate the fact that the discrimination of mentally ill persons hinders their recovery and the chance for playing a specified social role [24].

Occupational activity of a patient with schizophrenia. While considering playing social roles by the patients discussed, the aspect of employment of patients suffering from serious mental diseases cannot be omitted. Numerous and varied programmes have been developed worldwide, designed to provide assistance for schizophrenia patients in return to work. Initially, the form of protected employment was very popular, whereas recent attention has been paid to the necessity for undertaking employment on an open labour market. Employers very frequently wonder with what jobs they could employ persons with the experience of mental disease. Here, there are important factors, such as the degree of patient's recovery, his/her current wellbeing, way of functioning before the disease, as well as education and skills possessed. Undoubtedly, the first step towards recovery is a properly managed pharmacotherapy; however, the full recovery of a person with the experience of a mental disease requires the return to normal social and occupational life.

The business strategy of corporate social responsibility (CRS), which has recently been in fashion, is important. This strategy, called by some people a Utopia, consists in that entrepreneurs voluntarily adopt ethical, social and ecologic obligations which far exceed the minimum standards designated by the rules of law. This peak of achievements of business ethics is closely related, as much as possible, with the use of own potential to solve actually existing social problems, e.g. by facilitating the undertaking of work by patients with mental diseases. When such people begin work and comply with their obligations they create profit for the enterprise, and their life situation is radically improved. When such persons live on health benefit, this is not only a problem from the economic aspect, but it also leads to their withdrawal from social life, inability to fulfil themselves occupationally, which often evokes frustration, lower self-esteem, deterioration of wellbeing, and deepening of psychopathological symptoms.

K. Charzyńska, K. Kucharska and A. Mortimer in a report entitled 'Does employment promote the process of recovery from schizophrenia? A review of the existing evidence', draw attention to the fact that the concept of recovery has been formed over many years; however, there is still the lack of an ultimate explanation of the meaning of the term 'recovery', and clinical definitions focus on the presence or reduction of the symptoms of the disease. Referring to the traditional clinical approach, total remission is defined as the regaining of full pre-disease functioning. The objective of the study was assessment of the potential evidence for the relationship between employment and specific nonoccupational components, which are indicators of recovery, such as signs of remission, cognitive functions, social and emotional functioning, and the quality of life. The researchers pose the question whether or not employment may be a factor which facilitates the process of recovery. The quality of life, psychopathology and general wellbeing were the most frequently investigated results of the review, and employment was associated with positive changes in dimensions not closely related with work, such as activity during leisure time. Therefore, there is a need for long-term, randomized studies of the relationship discussed [25].

The goal of a large number of organizations worldwide is education, an increase in awareness, advocacy and campaigns targeted against the social stigmatization of mentally ill people. Below are some of these organizations functioning in Europe:

- EUFAMI: European Federation of Associations of Families of People with Mental Illness) - an organization which represents families which manages voluntary organizations taking care of the interests and welfare of all people affected by a serious mental disease.

- World Fellowship for Schizophrenia and Allied Disorders: an organization founded in order to improve the level of empathy and knowledge concerning schizophrenia, and also counteract the stigmatization and mistreatment of people suffering from this disease.

- Mental Health Europe: a non-government organization acting on behalf of the prevention of psychological stress, which promotes mental wellbeing and protects human rights.

- GAMIAN-Europe: the mission of this organization is improvement of the quality of life of mentally ill people and their families. 
- World Federation for Mental Health (WFMH): an organization with international membership, founded in order to prevent mental diseases and emotional disorders, and promote mental health.

\section{CONCLUSIONS}

The fact of underestimation of the importance of psychosocial interventions in the treatment of schizophrenia remains a constantly unsolved problem. Schizophrenia presents the contemporary world and its entire community with a serious problem - how to help people who do not seem to have the possibilities or are not willing to care for themselves, and who often conceal great potential? Sometimes, inpatient as well as outpatient treatment does not bring about positive effects, although anti-psychotic drugs reduce psychopathological symptoms; however, they do not act sufficiently effectively to be the method for restoring these patients' chances to fully exist in society. In order to avoid many personal, family, and social tragedies caused by schizophrenia, it is necessary to undertake a tremendous effort within the scope of widely understood psychosocial interventions [26].

Treatment, psychosocial interventions, and rehabilitation are aimed at the neutralization of the causes due to which patients withdraw from social life. The training of social skills is necessary, which would teach the patients how to return to the situation in which they will be able to independently function in society [10]. Restoration of health, i.e. recovery, is an important element for the patients' social functioning and life perspectives, the process of discovering and developing life strategy due to which they choose new or modified todate goals, values and life attitudes. It is about regaining hope, working-out proper attitudes towards the stereotype, negative connotations related with the disease, about the effect on one's own life, feeling of subjectivity, independence, and responsibility [27].

\section{REFERENCES}

1. Kępiński A. Schizofrenia. Warszawa; PZWL: 2012. ss.400. ISBN 978 83-77200-50-6.

2. DSM-5 American Psychiatric Association. "Diagnostic and statistical manual of mental disorders.” Arlington: American Psychiatric Publishing (2013).

3. Merton Robert K. The sociology of science: Theoretical and empirical investigations. University of Chicago press, 1973.

4. Seligman MEP, Walker EF, Rosenhan DL. Psychopatologia: Poznań; Zysk i S-ka: 2003. ss.864. ISBN 8372984417.

5. Jelastopulu E, Giourou E, Merekoulias G, Mestousi A, Moratis E, Alexopoulos EC. Correlation between the Personal and Social Performance scale (PSP) and the Positive and Negative Syndrome Scale (PANSS) in a Greek sample of patients with schizophrenia. BMC psychiatry 2014; 14(1): 197.

6. Jelastopulu E, Giourou E, Merekoulias G, Mestousi A, Moratis E, Alexopoulos EC. Correlation between the Personal and Social
Performance scale (PSP) and the Positive and Negative Syndrome Scale (PANSS) in a Greek sample of patients with schizophrenia. BMC psychiatry 2014; 14(1): 197.

7. Fioravanti M, et al. A meta-analysis of cognitive deficits in adults with a diagnosis of schizophrenia. Neuropsychology review 2005; 15(2): 73-95.

8. Kraguljac NV, Srivastava A, Lahti AC. Memory deficits in schizophrenia: a selective review of functional magnetic resonance imaging (FMRI) studies. Behavioral Sci. 2013; 3(3): 330-347.

9. Jarema M. Leksykon schizofrenii. Poznań; Termedia Wydawnictwa Medyczne: 2010. ss.134. ISBN: 978-83-62138-34-0.

10. Rynda M, Białecka-Pikul M. Dysfunkcja społeczna w schizofrenii z perspektywy poznania społecznego. Psychologia Społeczna 2010; 4(15): 345-354.

11. Ziolkowski A, Blachnio A, Pachalska M. An evaluation of life satisfaction and health-Quality of life of senior citizens. Ann Agric Environ Med. 2015; 22(1).

12. Armijo J, Méndez E, Morales R, Schilling S, Castro A, Alvarado R, Rojas G. Efficacy of community treatments for schizophrenia and other psychotic disorders: a literature review. Frontiers in psychiatry 2013; 4.

13. Elis O, Caponigro JM, Kring AM. Psychosocial treatments for negative symptoms in schizophrenia: current practices and future directions. Clin Psychol Rev. 2013; 33(8): 914-928.

14. Kwon JS, Choi JS. Funkcjonowanie społeczne i jakość życia jako miary efektywności w leczeniu schizofrenii. Post Psychiatrii Neurol. 2009; 18(2): 125-126.

15. Petrozolin-Skowrońska B, Wojnowski J (ed.) Nowa Encyklopedia Powszechna. T. 3. Warszawa; PWN: 1995. ISBN: 83-01-11967-5.

16. Chuchra M. Rodzina z dorosłym dzieckiem chorym na schizofrenię. Lublin: Wydawnictwo KUL: 2010. ss.541. ISBN: 978-83-7702-007-4.

17. Majkowicz M, Zdun-Ryżewska A. Ocena jakości życia w zaburzeniach psychicznych - koncepcje, badania, narzędzia pomiaru. Via Medica. 2009; 2(2): 110-114.

18. Rybakowski J, Suwalska A, Jaracz K, Górna K. Funkcjonowanie społeczne chorych z pierwszym epizodem schizofrenii w ocenie prospektywnej - wyniki wstępne. Psychiatria Polska 2008; 42(1): 33-46.

19. Ying Z H O U, Rongshan Z H O U, Wenjie L I, Yiqiang L I N, Jian Y A O, Jian C H E N, Tao S H E N. Controlled trial of the effectiveness of community rehabilitation for patients with schizophrenia in Shanghai, China. Shanghai Archives of Psychiatry 2015; 27(3): 167.

20. Štrkalj-Ivezić S, Vrdoljak M, Mužinić L, Agius M. The impact of a rehabilitation day centre program for persons suffering from schizophrenia on quality of life, social functioning and self-esteem. Psychiatria Danubina 2013; 25(2): 194-199.

21. Nakamura H, Watanabe N, Matsushima E. Structural equation model of factors related to quality of life for community-dwelling schizophrenic patients in Japan. Int J Mental Health Systems. 2014; 8(1): 32.

22. CBOS. Osoby chore psychicznie w społeczeństwie. Komunikat z badań. Warszawa; 2008.

23. Araszkiewicz A, Golicki D, Heitzman J, et al. Biała Księga. Osoby chorujące na schizofrenię w Polsce. Raport. Instytut Praw Pacjenta i Edukacji Zdrowotnej: 2011. ss.68. http://www.prawapacjenta.eu/ var/media/File/Zdrowie_psychiczne_Biala_Ksiega_2011_rok.pdf [dostęp:13.10.2015].

24. Świtaj P. Doświadczanie piętna społecznego i dyskryminacji u pacjentów z rozpoznaniem schizofrenii. Warszawa; Instytut Psychiatrii i Neurologii: 2008. ss. 223. ISBN: 978-83-85705-90-1.

25. Charzyńska K, Kucharska K, Mortimer A, Polańska K, Jurewicz J, Hanke W, Belanger-Gardner D. Does employment promote the process of recovery from schizophrenia? A review of the existing evidence. Int J Occup Med Environ Health 2015; 28(3): 407-418.

26. Carson RC, Butcher JN, Mineka S. Psychologia zaburzeń. Gdańsk; GWP: 2011. ss.1224. ISBN: 978-83-7489-375-6.

27. Pużyński S, Rybakowski J, Wciórka J, Psychiatria. Tom 2, wyd.II, Wrocław; Elsevier Urban \& Partner: 2011. ss.703.ISBN: 978-83-7609106-8. 